\title{
Role of oestradiol in growth of follicles and follicle deviation in heifers
}

\author{
M. A. Beg ${ }^{1,2}$, C. Meira ${ }^{1,2}$, D. R. Bergfelt ${ }^{1,2}$ and O. J. Ginther ${ }^{1,2 *}$ \\ ${ }^{1}$ Department of Animal Health and Biomedical Sciences, University of Wisconsin, Madison, WI 53706, \\ USA; and ${ }^{2}$ The Eutheria Foundation, Cross Plains, WI 53528, USA
}

Follicle deviation is characterized by continued growth of the largest (developing dominant) follicle and reduced growth of the smaller (subordinate) follicles. The aim of the present study was to test the following hypotheses: (1) oestradiol contributes to the depression of circulating FSH encompassing follicle deviation and (2) oestradiol plays a role in the initiation of deviation. Heifers were treated with progesterone $(n=5)$ or antiserum against oestradiol $(n=7)$ or given no treatment (control; $n=6$ ). On the basis of previous studies, progesterone treatment would decrease LH and thereby the circulatory and intrafollicular concentrations of oestradiol and the antiserum would reduce the availability of oestradiol. Progesterone was given in six $\mathbf{7 5} \mathrm{mg}$ injections at $\mathbf{1 2} \mathrm{h}$ intervals beginning when the largest follicle of wave 1 first reached $\geqslant 5.7 \mathrm{~mm}$ $(t=0 \mathrm{~h})$. Oestradiol antiserum $(100 \mathrm{ml})$ was given in a single injection at $t=12 \mathrm{~h}$. Follicles of the wave were defined as F1 (largest) and F2, according to the diameter at each examination. Blood samples were collected at $12 \mathrm{~h}$ intervals during $t=0-72 \mathrm{~h}$. Treatment with progesterone lowered the circulatory concentrations of LH by $12 \mathrm{~h}$ after the start of treatment $(P<0.05)$, and concentrations remained low compared with those of controls during the treatment period. Treatment with oestradiol antiserum had no effect on LH. Both progesterone and the antiserum treatments increased the FSH concentrations compared with controls $(P<0.05)$, which supports the first hypothesis. The interval from $t=0 \mathrm{~h}$ to the beginning of deviation was longer in the progesterone- $(51.0 \pm 7.6 \mathrm{~h} ; P<0.06)$ and antiserum (51.4 $\pm 6.3 \mathrm{~h} ; P<0.05)$-treated groups than in the controls $(38.0 \pm 3.7 \mathrm{~h})$, which supports the second hypothesis. There was no difference among groups in the diameters of F1 and F2 at deviation. Reduced diameter $(P<0.05$ or $P<0.06)$ of both $F 1$ and $F 2$ occurred in both the progesterone- and antiserum-treated groups at $t=36 \mathrm{~h}$ and $48 \mathrm{~h}$, compared with controls. Follicle retardation occurred in both the progesterone- and antiserum-treated groups despite the high FSH concentrations, whereas LH was altered only in the progesterone-treated group. Therefore, the follicle effect can be attributed to inadequate intrafollicular oestradiol. This interpretation implies a functional local role for oestradiol in the deviation process, independent of the systemic negative effect on FSH.

\section{Introduction}

Follicle selection during a follicular wave in cattle involves deviation in diameters between the two largest follicles (for review, see Ginther et al., 2001a). Deviation is characterized by continued growth of the largest (developing dominant) follicle and cessation or reduced growth of the smaller (subordinate) follicles. On the basis of several studies, the mean diameter of the largest follicle in heifers at the beginning of deviation is $8.5 \mathrm{~mm}$. Emergence of a follicular wave is stimulated by an $\mathrm{FSH}$ surge that reaches its peak when the largest follicle of the wave is about $5 \mathrm{~mm}$. Thereafter, FSH concentrations decrease and reach basal concentrations shortly after the

\footnotetext{
*Address for correspondence: Department of Animal Health and Biomedical Sciences, 1656 Linden Drive, University of Wisconsin, Madison, WI 53706, USA

Email: ojg@ahabs.wisc.edu
}

beginning of deviation. During a common growth phase, multiple follicles contribute to the sustained decline in circulating FSH, yet the follicles continue to require $\mathrm{FSH}$. By the end of the common growth phase (beginning of deviation), the largest follicle is more responsible for continuation of the FSH decline to nadir concentrations and better utilizes the low concentrations of $\mathrm{FSH}$ than do the smaller follicles. Enhanced sensitivity or responsiveness of the future dominant follicle to $\mathrm{FSH}$ and $\mathrm{LH}$ apparently accounts for its differential growth during deviation. Intrafollicular oestradiol, insulin growth factor I (IGF-I), and activin peptides appears to be involved in increasing the gonadotrophin responsiveness of the developing dominant follicle (Ginther et al., 2002).

Circulating oestradiol and inhibin are candidates for the decline in FSH concentration after the wavestimulating surge reaches peak concentration (Ginther et al., 2001a). However, the relative contribution of the two FSH suppressors during various parts of the 
FSH decline have not been clarified. Shortly before or at the beginning of deviation in heifers, follicular fluid concentrations of oestradiol begin to increase differentially in the future dominant follicle compared with the future largest subordinate follicle (Ginther et al., 1997a; Beg et al., 2001, 2002). Similarly, an increase in circulating oestradiol begins near the beginning of diameter deviation and is attributable to the largest follicle (Ginther et al., 2000). A decrease in FSH was observed in cattle after treatment with exogenous oestradiol during the common growth phase or at the beginning of deviation (Ginther et al., 2000). Passive immunization against oestradiol has been used to study the role of oestradiol but not in relation to deviation (Kaneko et al., 1995). In vitro and in vivo studies in laboratory animals (for reviews, see Drummond and Findlay, 1999; Rosenfeld et al., 2001) have shown that oestradiol promotes follicle growth and granulosa cell proliferation, enhances aromatase activity and increases the sensitivity of granulosa cells to $\mathrm{FSH}$ and $\mathrm{LH}$ by potentiating granulosa cell expression of $\mathrm{FSH}$ and LH receptors. Apparently, the roles of oestradiol in deviation in cattle are to contribute to circulating FSH suppression and to increase intrafollicular gonadotrophin responsiveness of the developing dominant follicle.

A transient increase in circulating concentrations of $\mathrm{LH}$ encompasses the beginning of deviation in cattle (Ginther et al., 2001a) and has been experimentally reduced by progesterone administration (Ginther et al., 2001 b,c). The reduced LH concentration was associated with lower intrafollicular and circulatory concentrations of oestradiol and intrafollicular concentrations of free IGF-I at the beginning of deviation and decreased diameter of the dominant follicle shortly after the beginning of deviation (Ginther et al., 2001b). The interval from beginning of treatment to the beginning of deviation was longer but not significantly different between the progesterone-treated and control groups. However, the frequency of prolonged intervals was significantly greater in the progesterone-treated group. The effects of progesterone treatment on the time of deviation, therefore, were considered equivocal, and require further study.

A dominant follicle was defined as a follicle that reaches $>10 \mathrm{~mm}$; and waves with codominant follicles frequently had two deviations (Kulick et al., 2001). The first deviation occurred when the diameter of the largest follicle was a mean of $8.5 \mathrm{~mm}$ and involved regression of the third-largest follicle. The second deviation involved the two dominant follicles. Kulick et al. (2001) reported that heifers with codominant follicles have higher gonadotrophin concentrations before and lower $\mathrm{FSH}$ concentrations after the first deviation.

The aim of the present study was to test the following hypotheses: (1) oestradiol contributes to the depression of circulating FSH encompassing deviation and (2) oestradiol plays a role in the initiation of deviation. The hypotheses were tested indirectly by administration of progesterone to reduce $\mathrm{LH}$ and therefore oestradiol, and directly by administration of an oestradiol antiserum. In addition, the relationship of codominance to gonadotrophin concentrations before and after deviation was considered.

\section{Materials and Methods}

\section{Animals and experimental groups}

The experiment was conducted during the follicle wave that emerges near the time of ovulation (wave 1). Holstein heifers between 24 and 36 months of age and body weight of 490-680 kg were used in the study. The feeding programme and the $\mathrm{PGF}_{2 \alpha}$ (Lutalyse, Pharmacia $\mathrm{Co}$, Kalamazo, MI) protocol for inducing luteolysis to schedule ovulation and the equipment and techniques for transrectal ultrasonography of ovaries and measuring follicles have been described (Ginther et al., 1999). Luteolysis was induced 6-8 days after ovulation. When the largest follicle of the new wave (wave 1 ) reached $\geqslant 5.7 \mathrm{~mm}$ in diameter $(t=0)$, heifers were randomized into three groups. Heifers in a progesterone-treated group $(n=5)$ received $75 \mathrm{mg}$ progesterone in $2 \mathrm{ml}$ of safflower oil vehicle i.m. every $12 \mathrm{~h}$ for a total of six injections. The progesterone dose and treatment regimen to reduce the circulating $\mathrm{LH}$ concentration were based on previous studies (Adams et al., 1992a; Ginther et al., 2001b). It was estimated that initiation of treatment when the largest follicle first reached $\geqslant 5.7 \mathrm{~mm}$ would precede and interfere with the increase in $\mathrm{LH}$ associated with deviation. Heifers in the oestradiol antiserum-treated group $(n=7)$ received $100 \mathrm{ml}$ of antiserum in a single i.v. bolus injection $12 \mathrm{~h}$ after the largest follicle reached $\geqslant 5.7 \mathrm{~mm}$. The $12 \mathrm{~h}$ interval used was on the basis of previous studies (Ginther et al., 2001b,c) in which plasma LH concentrations were not significantly lower at $12 \mathrm{~h}$ but were lower at $24 \mathrm{~h}$ after the first injection of progesterone. A control group $(n=6)$ of heifers did not receive any treatment.

\section{Ultrasonography and definitions}

Beginning at the $\mathrm{PGF}_{2 \alpha}$ injection, the heifers were scanned every $12 \mathrm{~h}$ until $t=120 \mathrm{~h}$ and then every $24 \mathrm{~h}$ until the end of the experiment when the largest follicle of the next wave first reached $>6 \mathrm{~mm}$. The experiment involved altering the $\mathrm{FSH}$ surge that stimulates the emergence of wave 1 . The time of emergence of the associated wave 1 was based on the first follicle that reached $\geqslant 4.0 \mathrm{~mm}$ in diameter and continued to grow. The two largest follicles were defined as F1 (largest follicle) and F2 (second-largest follicle), according to their diameter at each examination and were used to assess the effects of treatment on follicles. The time at the start of deviation in follicle diameter 
was identified in retrospect by observation, using the growth profiles of $\mathrm{F} 1$ and F2, without knowledge of group, as described by Ginther et al. (1997b). In one heifer in the progesterone-treated group, F2 reached a maximum of only $6 \mathrm{~mm}$ in diameter and was omitted in estimating the time of observed deviation, but was included in the analysis of the other end points. For the heifers with codominant follicles (> $10 \mathrm{~mm}$; Kulick et al., 2001), the largest follicle was designated F1, and the third-largest follicle was used for F2 (largest subordinate follicle) in the diameter analyses and for determining the time of deviation that corresponds to deviation for heifers with one dominant follicle. A second deviation that reportedly (Kulick et al., 2001) occurs between the two dominant follicles after both the diameters of follicles are $>10 \mathrm{~mm}$ was recorded.

\section{Preparation of oestradiol antiserum}

Oestradiol antiserum used in this study was prepared in goats according to the protocol for raising oestradiol antiserum in goats described by Kaneko et al. (1995). The antigen 1,3,5(10)-oestratrien-3,17 $\beta$-diol-6-one 6carboxymethyloxime conjugated to BSA (Steraloids Inc., Newport, RI) was dissolved $\left(1 \mathrm{mg} \mathrm{ml}^{-1}\right)$ in saline $(0.9 \%$, $\mathrm{w} / \mathrm{v}$ ) and emulsified in an equal volume of Freund's complete adjuvant (Sigma Chemical Co., St Louis, MO) and used for primary immunization in three castrated goats $(2 \mathrm{mg}$ conjugated oestradiol per goat) by s.c. injection at multiple sites. A booster injection of $1 \mathrm{mg}$ oestradiol conjugate emulsified in Freund's incomplete adjuvant (Sigma) was injected every 3-4 weeks, and antiserum was obtained on days 7-10 after each booster injection. The titre of the oestradiol antiserum was determined as described by the International Atomic Energy Authority (1984). Briefly, different dilutions of antiserum were run in an assay with fixed amounts of iodinated oestradiol tracer $\left({ }^{125} \mathrm{I}\right)$. The greatest dilution of oestradiol antiserum that bound $50 \%$ of the tracer was selected as the titre of the antiserum. Two of the three goats developed a high titre of the antibody and the antiserum was pooled from these two goats. The final titre of the antiserum was 1:256 000. A pilot study was conducted to determine a volume sufficient to reduce the bioavailability of circulating oestradiol. Oestradiol antiserum in doses of 25,50 and $100 \mathrm{ml}$ and control goat serum in a dose of $100 \mathrm{ml}$ were injected into heifers (three heifers per group) as an i.v. bolus $36 \mathrm{~h}$ after induction of luteolysis with $\mathrm{PGF}_{2 \alpha}$. Plasma samples were collected every $6 \mathrm{~h}$ after injection until $t=108 \mathrm{~h}$ and every $12 \mathrm{~h}$ thereafter. The interval from injection to the peak of the preovulatory LH surge was longer in one heifer in the $50 \mathrm{ml}$ antiserum group $(48 \mathrm{~h})$ and in two heifers in the $100 \mathrm{ml}$ antiserum group ( $24 \mathrm{~h}$ and $36 \mathrm{~h}$ ) than in any of the six heifers in the $100 \mathrm{ml}$ control serum and $25 \mathrm{ml}$ antiserum groups (12-18 h). Thus a dose of $100 \mathrm{ml}$ antiserum was chosen. In a separate pilot study, a
$100 \mathrm{ml}$ bolus of antiserum injected i.v. when the largest follicle of wave 1 was $9.0 \mathrm{~mm}$ resulted in an increase in FSH concentrations for $48 \mathrm{~h}$ in one of two heifers.

\section{Hormone assays}

Jugular venous blood samples were collected every $12 \mathrm{~h}$ starting at $\mathrm{PGF}_{2 \alpha}$ injection and continued until $t=72 \mathrm{~h}$. Samples were collected into heparinized tubes and plasma was separated by centrifugation at $1500 \mathrm{~g}$ for $20 \mathrm{~min}$, decanted into storage vials, and frozen at $-20^{\circ} \mathrm{C}$ until assay. Plasma concentrations of FSH and $\mathrm{LH}$ were determined by radioimmunoassay procedures that have been described and validated for bovine plasma in the authors' laboratory (Adams et al., 1992b; Ginther et al., 2000). The standards and antibodies were provided by A. F. Parlow (National Hormone and Peptide Program, Torrance, CA). The intra- and interassay CV for quality control samples and the mean assay sensitivity, respectively, were $8.4 \%, 2.7 \%$ and $0.01 \mathrm{ng} \mathrm{ml}^{-1}$ for $\mathrm{FSH}$ ( $n=2$ assays), and $7.1 \%, 7.0 \%$ and $0.14 \mathrm{ng} \mathrm{ml}^{-1}$ for $\mathrm{LH}$ ( $n=2$ assays).

\section{Statistical analysis}

The follicular and hormonal data were tested for normality using Kolmogorov-Smirnov test and suspected outliers were challenged using Dixon's outlier test (Kanji, 1993). Five of 126 observations for LH (4.0\%) were determined to be statistical outliers and were excluded from further analysis. Outliers were not detected for the other end points. For diameter and plasma concentrations of $\mathrm{LH}$, the data were not normally distributed and were transformed logarithmically before analysis. The concentrations of FSH were converted to percentage change from the concentrations at $t=0$ (first progesterone treatment). Percentages were used because of a difference $(P<0.05)$ between the means of antiserum and control groups at $t=0$ (before treatment). It was thought that the disparity could contribute to significant differences at later times. In this regard, percentage conversion of $\mathrm{FSH}$ values was used in a previous study for this reason and because of a significant correlation in FSH concentrations among days within heifers (Ginther et al., 2001c). Follicle data, plasma concentrations of $\mathrm{LH}$ and ranked (Kruskal-Wallis test) percentage data for FSH were analysed with SAS Mixed procedure with a repeated statement to account for autocorrelation between sequential measurements. The means within an hour or group were compared with Duncan's multiple-range test or Student's $t$ test. Single point measurements for follicle end points were analysed by one-way ANOVA. A probability of $P \leqslant 0.05$ indicated that the difference was significant, and probabilities between $P>0.05$ and $P<0.1$ were considered as approaching significance. 


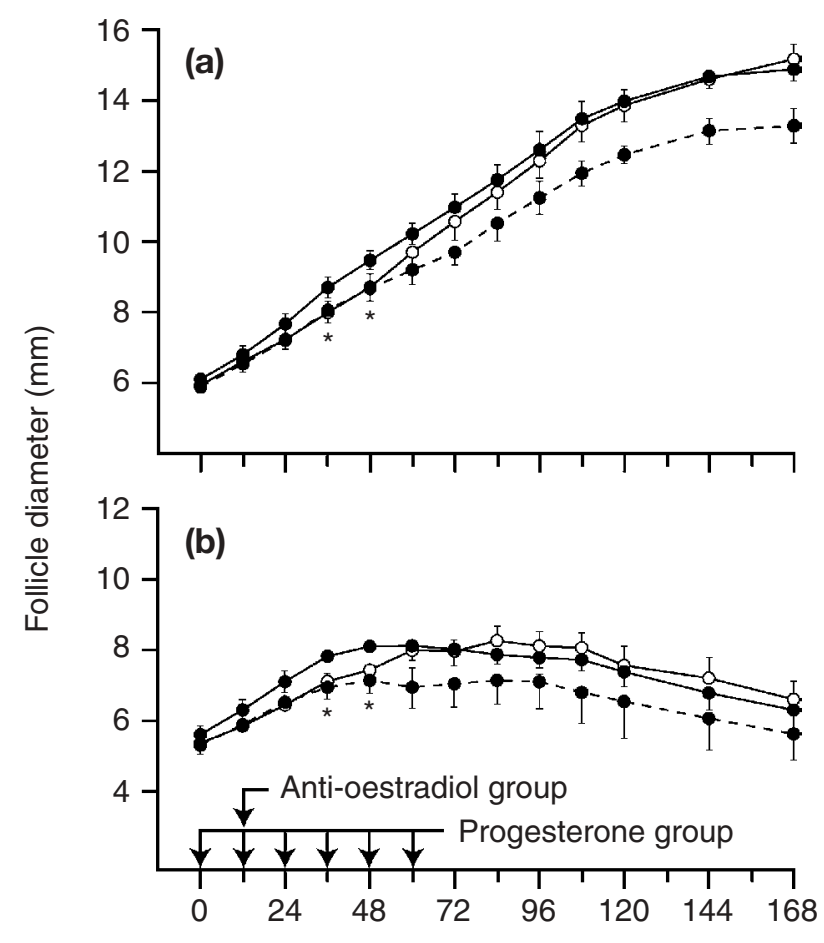

Time (h) from start of progesterone treatment

Fig. 1. Mean \pm SEM diameter of (a) largest follicle (F1) and (b) second-largest follicle (F2) in heifers given progesterone (----, $n=$ $5)$, oestradiol antiserum ( $\bigcirc-, n=7$ ), or no treatment (control; $-1, n=6)$. The arrows indicate progesterone treatment every $12 \mathrm{~h}$ starting when $\mathrm{F} 1$ first reached $\geqslant 5.7 \mathrm{~mm}(t=0)$ and oestradiol antiserum as a single injection at $t=12 \mathrm{~h}$. There was a main effect of time (h) $(P<0.0001)$ for each follicle and a group effect $(P<0.04)$ for F1 only. The asterisks $\left(^{*}\right)$ indicate the times when both F1 and F2 of both progesterone- and antiserum-treated groups were smaller $(P<0.05$ or $P<0.06)$ than in the control group. In addition, the diameter of $\mathrm{F} 1$ was smaller $(P<0.05)$ in the progesterone-treated group than in the control group for each of $t=60-168 \mathrm{~h}$.

\section{Results}

On average, the nadir at the onset of the FSH surge associated with wave 1 occurred at $t=-32 \pm 2.5 \mathrm{~h}(t=0$
$=$ largest follicle $>5.7 \mathrm{~mm}$ ) when the diameter of F1 was $4.2 \pm 0.1 \mathrm{~mm}$, and the peak occurred at $t=-6.0 \pm 6.8 \mathrm{~h}$ when diameter was $5.6 \pm 0.3 \mathrm{~mm}$. The actual diameter of $\mathrm{F} 1$ at $t=0$ (start of progesterone treatment) was $6.1 \pm 0.1 \mathrm{~mm}$ for the controls and $5.9 \pm 0.1 \mathrm{~mm}$ for the progesterone-treated group. Diameter of $\mathrm{F} 1$ at $t=$ $12 \mathrm{~h}$ (time of single injection of oestradiol antiserum) was $6.8 \pm 0.2 \mathrm{~mm}$ in the controls and $6.6 \pm 0.2 \mathrm{~mm}$ in the antiserum-treated group. The mean changes in the diameter of F1 and F2 are presented (Fig. 1). A group effect for $\mathrm{F} 1$ resulted from a smaller $(P<0.04)$ overall mean diameter in the progesterone-treated group $(9.8 \pm 0.3 \mathrm{~mm})$ than in the control group $(10.9 \pm 0.2$ $\mathrm{mm})$ or oestradiol antiserum-treated group $(10.6 \pm 0.2$ $\mathrm{mm})$. The diameter of F1 tended to be smaller $(P<0.06)$ at $t=36 \mathrm{~h}$ for the progesterone-treated group than in the controls and was significantly smaller $(P<0.05)$ at all times, thereafter. The diameter of F1 was smaller $(P<0.04)$ in the oestradiol antiserum-treated group than in controls at $t=36 \mathrm{~h}$ and tended to be smaller $(P<0.06)$ at $t=48 \mathrm{~h}$. The diameter of $\mathrm{F} 2$ was smaller $(P<0.009$ 0.02 ) in each of the progesterone- and antiserum-treated groups than in the control group at $t=36 \mathrm{~h}$ and $48 \mathrm{~h}$. The maximum diameter of $\mathrm{F} 1$ was smaller $(P<0.05)$ in the progesterone-treated group than in the antiserumtreated and control groups, whereas there were no significant effects for maximum diameter of $\mathrm{F} 2$ (Table 1).

The effects of progesterone and antiserum treatment on the time of observed deviation and diameter of $\mathrm{F} 1$ and F2 at deviation are shown (Table 1). The interval from $t=0$ to observed deviation $(P<0.06)$ was longer in the progesterone-treated group and $(P<0.05)$ in the antiserum-treated group than in the control group. There was no significant difference among the three groups for the diameter of F1 or F2 at observed deviation. Follicle data for each group normalized to the ultrasound examination that was closest to the mean time of deviation in the controls are shown (Fig. 2).

A group effect $(P<0.04)$ for plasma LH concentrations reflected lower average concentration in the

Table 1. Mean \pm SEM for end points following treatment with progesterone or oestradiol antiserum in heifers

\begin{tabular}{lccc}
\hline End point & Control group & Progesterone-treated group & Oestradiol antiserum-treated group \\
\hline Number of heifers & 6 & 5 & 7 \\
Interval from $t=0$ to & $38.0 \pm 3.7^{\mathrm{a}}$ & $51.0 \pm 7.6^{\mathrm{b}}$ & $51.4 \pm 6.3^{\mathrm{b}}$ \\
$\quad$ & & & $8.4 \pm 0.2$ \\
beginning of deviation $(\mathrm{h})$ & $8.7 \pm 0.2$ & $7.6 \pm 0.3$ & 0.2 \\
Diameter of F1 at deviation $(\mathrm{mm})$ & $8.0 \pm 0.2$ & $13.5 \pm 0.3^{\mathrm{b}}$ & $8.0 \pm 0.3$ \\
Diameter of F2 at deviation $(\mathrm{mm})$ & $15.1 \pm 0.3^{\mathrm{a}}$ & $7.7 \pm 0.6$ & $16.3 \pm 0.8^{\mathrm{a}}$ \\
Maximum diameter of F1 $(\mathrm{mm})$ & $8.3 \pm 0.1$ & $8.6 \pm 0.3$ \\
Maximum diameter of F2 $(\mathrm{mm})$ & & \\
\hline
\end{tabular}

Progesterone treatment was started when the largest follicle (F1) was $\geqslant 5.7 \mathrm{~mm}(t=0)$ and continued every $12 \mathrm{~h}$ for six injections. Oestradiol antiserum treatment was given in a single injection at $t=12 \mathrm{~h}$.

a,b Means with different superscripts within a row are significantly different $(P<0.05)$, except that the difference between controls and the progesterone-treated group for interval to deviation approached significance $(P<0.06)$. 


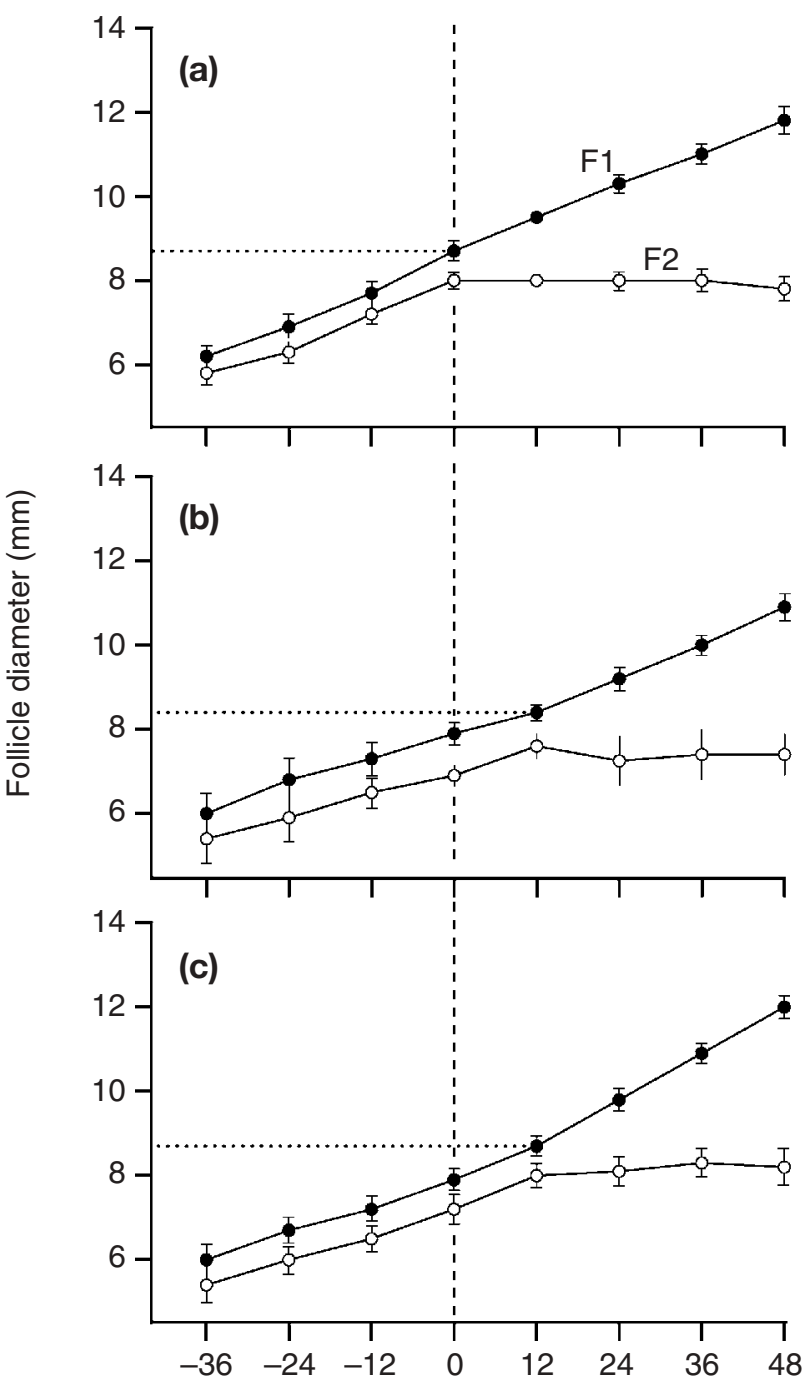

Time (h) from beginning of deviation in controls

Fig. 2. Mean \pm SEM diameter of largest follicle (F1; - and second-largest follicle (F2; - - ) in heifers in (a) control ( $n=6)$, (b) progesterone-treated $(n=4)$ and (c) oestradiol antiserum-treated $(n=7)$ groups. Data within each group are normalized to the ultrasound examination nearest to the mean time (h) of deviation (vertical broken line) relative to the controls. Mean observed beginning of deviation was delayed $12 \mathrm{~h}$ in the two treated groups. Note the similarity among groups in the diameter of $\mathrm{F} 1$ at the beginning of deviation (horizontal dotted line).

progesterone-treated group than in the antiserum-treated and control groups (Fig. 3). When each treatment group was compared separately with the control group, the group effect was significant $(P<0.02)$ for the progesterone-treated versus control groups but not for the antiserum-treated versus control groups. A time effect $(P<0.002)$ reflected an increase in plasma $\mathrm{LH}$ concentration $(P<0.05)$ between $t=24 \mathrm{~h}$ and $48 \mathrm{~h}$ and a decrease $(P<0.05)$ between $t=48 \mathrm{~h}$ and $72 \mathrm{~h}$
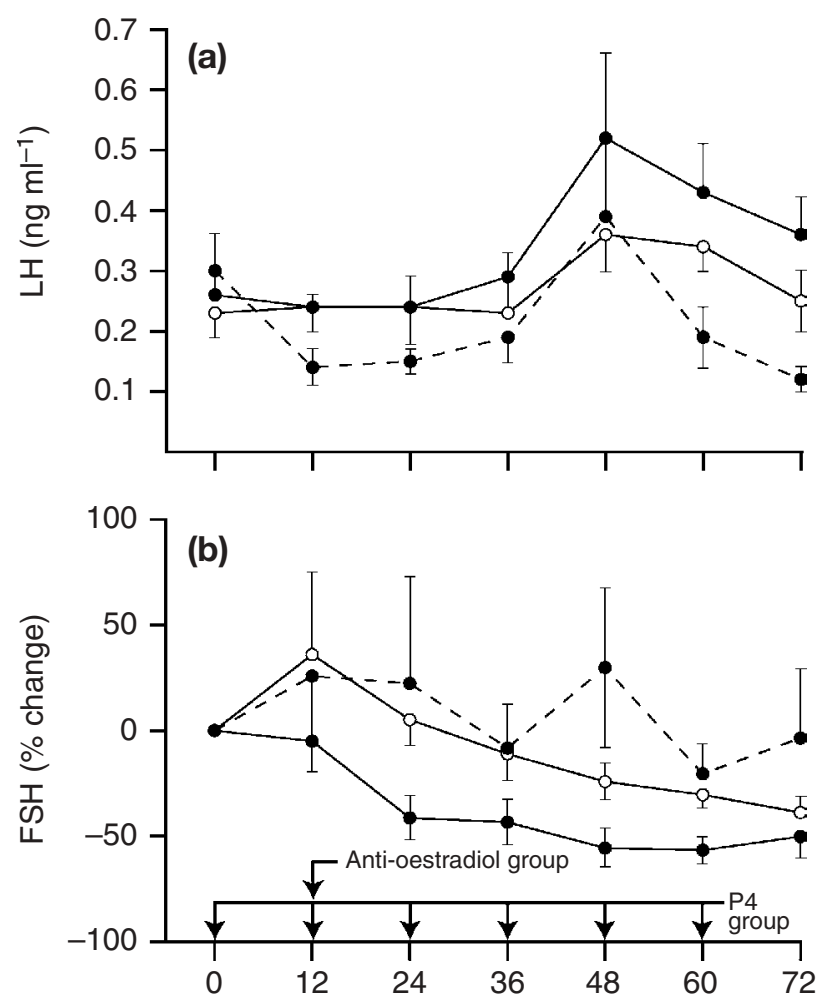

Time (h) from start of progesterone treatment

Fig. 3. Mean \pm SEM concentrations of (a) $\mathrm{LH}$ and percentage change in concentrations of (b) $\mathrm{FSH}$ in heifers given progesterone (--๑--, $n=5)$, oestradiol antiserum ( $-\bigcirc-, n=7$ ) or no treatment (control; - - $n=6$ ). The arrows indicate progesterone (P4) treatment every $12 \mathrm{~h}$ starting when F1 first reached $\geqslant 5.7 \mathrm{~mm}$ in diameter $(t=0 \mathrm{~h})$ and oestradiol antiserum as a single injection at $t=12 \mathrm{~h}$. There were main effects of group $(P<0.04)$ and time (h) $(P<0.002)$ for both $\mathrm{LH}$ and FSH.

averaged over the three groups. A group effect $(P<0.04)$ for FSH involved higher average concentrations, based on percentage change, in each of the two treated groups than in the controls (Fig. 3). There was no significant difference between the two treated groups.

Codominance (more than one follicle $>10 \mathrm{~mm}$ ) was detected in one heifer in the progesterone group and two heifers in each of the antiserum-treated and control groups. A second deviation (Fig. 4) occurred in each of the five heifers with codominant follicles at a mean of $36.0 \pm 8.5 \mathrm{~h}$ after the first deviation when the two dominant follicles were $10.9 \pm 0.4$ and $10.2 \pm 0.2 \mathrm{~mm}$ in diameter. The FSH concentrations for heifers with single dominant versus double dominant follicles are shown (Fig. 4). The concentrations were lower in the codominant group at $24 \mathrm{~h}$ (approached significance, $P<0.09)$, $36 \mathrm{~h}(P<0.04)$ and $48 \mathrm{~h}(P<0.05)$ after the first deviation. Concentrations of $\mathrm{LH}$ were not significantly different between single and codominant groups and are not presented. 


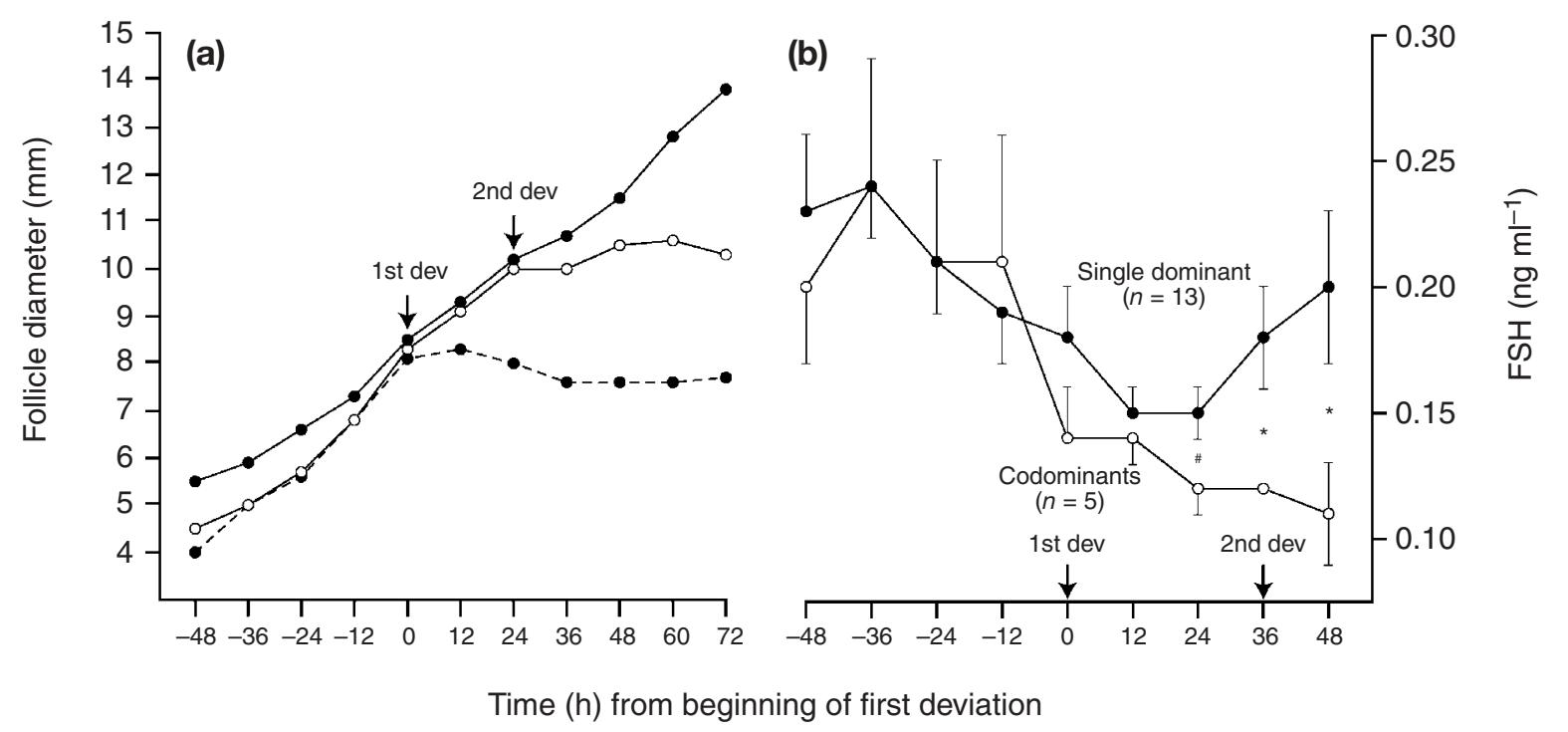

Fig. 4. (a) Diameter of largest (-——), second-largest (-○—) and third-largest (----) follicles in an individual heifer showing the beginning of two deviations. (b) Mean \pm SEM concentrations of FSH associated with wave 1 for single dominant (-—) and codominant (-O—) follicular waves (two follicles $>10 \mathrm{~mm}$ ) and the mean time (h) of the second deviation relative to first deviation. The time effect for FSH was significant $(P<0.001)$ and the group effect approached significance $(P<0.08)$. The asterisks $\left(^{*}\right)$ indicate the times with a difference between groups $(P<0.05)$ and hash sign $(\#)$ indicates approaching significance $(P<0.09)$. dev: deviation.

\section{Discussion}

In the present study, there was considerable variability in the $\mathrm{FSH}$ surge associated with wave 1 , as indicated by the occurrence of an $\mathrm{FSH}$ peak in controls ranging from 12 to $48 \mathrm{~h}$ after the beginning of the surge among individuals and an FSH concentration at the peak ranging from $0.25 \mathrm{ng} \mathrm{ml}^{-1}$ to $1.16 \mathrm{ng} \mathrm{ml}^{-1}$. Apparent fluctuations for some individuals were masked in the average profile. In this regard, a previous study using blood sampling every $6 \mathrm{~h}$ indicated that significant multiple fluctuations were superimposed on the wave-stimulating surge in most individuals (Bergfelt et al., 1997). Experimentally increasing the FSH concentrations with exogenous FSH or an anti-inhibin antibody beginning before deviation interferes with deviation and favours the development of multiple dominant follicles (for reviews, see Ginther et al., 1996, 2001a). These reported results indicate that low FSH concentrations are needed for deviation to begin. The fluctuations and variability in the profile of the FSH surge in the present study compared with the consistent follicle diameters among groups at deviation indicate that the onset of deviation occurs when the most advanced follicle reaches a certain developmental stage in the presence of low FSH concentrations and that much variation is tolerated in the low or changing FSH concentrations.

The decrease in $\mathrm{LH}$ concentrations by $t=12 \mathrm{~h}$ and the increase in FSH concentrations by $t=24 \mathrm{~h}$ in the progesterone-treated group are in agreement with the results of similar studies (Ginther et al., 2001b,c). Passive immunization with a single injection of oestradiol antiserum resulted in increased plasma $\mathrm{FSH}$ concentrations, similar to the response to progesterone treatment. However, oestradiol antiserum did not affect plasma LH concentrations. In reported studies in cattle, oestradiol antiserum did not affect the basal LH and FSH concentrations but did interfere with the preovulatory surges (Kaneko et al., 1995, 2002). The reasons for the apparent differences between these reported results and the results of the present study on the effects of oestradiol antiserum on plasma gonadotrophins are not known. However, unlike the previous studies, the present study focused on the events encompassing follicle deviation when the concentrations of both $\mathrm{LH}$ and $\mathrm{FSH}$ are much lower than during the preovulatory period. In this regard, the antiserum dose used in this study delayed the occurrence of the preovulatory $\mathrm{LH}$ peak in the preliminary study, even though an effect on LH was not detected near the time of deviation in the principal experiment.

The effect of progesterone treatment on concentrations of oestradiol was not studied because the negative effect of exogenous progesterone and the resulting reduction in LH on circulating and intrafollicular oestradiol was shown previously in similar studies in cattle (Ginther et al., 2001b,c). In the oestradiol antiserum-treated group, the concentrations of oestradiol were not determined because of the presence of antibodies in circulation. However, the effectiveness of the antiserum in 
neutralizing oestradiol was indicated indirectly by the positive effect on FSH and the negative effect on follicles. Thus, the hypothesis that systemic oestradiol contributes to the continuing depression of FSH encompassing deviation is supported by the results of both the progesteronetreated group and oestradiol antiserum-treated group. Higher plasma FSH concentrations after treatment with either progesterone or oestradiol antiserum are consistent with the reported temporal relationships between increasing oestradiol and decreasing FSH concentrations and with the negative effect of exogenous oestradiol on FSH (Ginther et al., 2000).

The hypothesis that oestradiol contributes to the initiation of deviation was supported by the mean delay of approximately $13 \mathrm{~h}$ in the interval from $t=0$ to the beginning of deviation in both the progesterone and antiserum groups. The negative effect of progesterone on F1 and F2 diameters at $t=36 \mathrm{~h}$ (near the time of deviation in controls) and $t=48 \mathrm{~h}$ and continuing for $\mathrm{F} 1$ until $t=168 \mathrm{~h}$ (end of study) is similar to the results of previous studies (Ginther et al., 2001b,c), except that the negative effect on diameter was reported only for $\mathrm{F} 1$ and was first detected 1.0 and 1.5 days after the beginning of deviation. For both progesterone and antiserum treatments, the reduced diameters of $\mathrm{F} 1$ at $t=36 \mathrm{~h}$ and $48 \mathrm{~h}$ were similar to the diameters in controls at $t=24 \mathrm{~h}$ and $36 \mathrm{~h}$, respectively. At the beginning of observed deviation, there were no differences in F1 or F2 diameters among groups. That is, about $12 \mathrm{~h}$ of growth was needed in the treated heifers for F1 and F2 to reach diameters that were similar to diameters in controls at the beginning of deviation. Apparently, oestradiol is required for growth of the two largest follicles near the beginning of deviation, and deviation was thereby delayed until the follicles reached characteristic diameters. This interpretation is consistent with the concept that the initiation of deviation is dependent, at least in part, on the attainment of a specific stage of development by the most advanced follicle.

A delay in the occurrence of deviation in progesterone-treated, LH-reduced and oestradiolreduced heifers was equivocal in a study by Ginther et al. (2001b), but was demonstrated in the progesteronetreated group of the present study. The delay in the occurrence of deviation in both the progesterone- and antiserum-treated groups could be attributed to the increased FSH. However, increased FSH is not a likely reason for the delayed deviation because: (1) increased FSH concentration is not compatible with reduced diameter of follicles at $t=36 \mathrm{~h}$ and $48 \mathrm{~h}$; (2) the number of dominant follicles or the maximal diameter of $\mathrm{F} 2$ did not increase, as occurs when FSH concentrations are increased with exogenous FSH before deviation; and (3) the fluctuations in the FSH profiles and the variation in the temporal FSH and follicle relationships in the controls diminishes the concept that a certain concentration of $\mathrm{FSH}$ is required for the initiation of deviation. In addition, short-term alterations in the patterns of $\mathrm{FSH}$ concentration induced by exogenous oestradiol or progesterone and their combinations did not alter the number of follicles emerging during wave 1 or the diameter of the early dominant follicle (mean diameters, 9.1-9.7 mm; Austin et al., 2002). That the delayed deviation resulted directly from reduced $\mathrm{LH}$ also does not seem likely because the $\mathrm{LH}$ reduction did not occur in the oestradiol antiserum-treated group. However, the reduced diameters of F1 after the occurrence of deviation $(t=60-168 \mathrm{~h})$ in the progesterone group is attributable to reduced $\mathrm{LH}$, based on the results of several previous studies in heifers and mares (for review, see Ginther et al., 2001a).

It has been shown that progesterone treatment and the resulting decrease in $\mathrm{LH}$ reduces both circulating and intrafollicular oestradiol concentrations (Ginther et al., 2001b,c). It seems reasonable that the oestradiol antiserum would reduce the availability of oestradiol in the follicle as well as in the circulation, but this was not demonstrated directly. The effect of oestradiol on follicular cell proliferation and differentiation has been studied extensively. Oestrogen stimulates the proliferation of granulosa cells and stimulates follicular growth and development in rats and cattle (Richards, 1980; Hulshof et al., 1995; Bley et al., 1997), increases the sensitivity of granulosa cells to $\mathrm{FSH}$ and $\mathrm{LH}$ by promoting granulosa cell expression of their receptors in rats (Richards, 1980), enhances steroidogenesis in granulosa and theca cells in cattle (Fortune and Quirk, 1988), increases the synthesis of other mitogenic factors such as IGF-I from granulosa cells in pigs (Hsu and Hammond, 1987) and regulates gap junction formation between granulosa cells which permit the transport of nutrients and other biochemical factors in the follicle in rats (Burghardt and Anderson, 1981). These reported results are consistent with the interpretation that retarded growth of the follicles at $t=36 \mathrm{~h}$ and $48 \mathrm{~h}$ and the resulting delayed deviation in both treatment groups in the present study are attributable directly to deficient intrafollicular concentrations of oestradiol.

The incidence of codominant follicles during wave 1 $(28 \%)$ in the present study was similar to that reported by Kulick et al. (2001). The five waves with codominance were distributed over the three experimental groups and did not appear to confound the other aspects of the study. Codominant follicles were not associated with higher concentrations of $\mathrm{LH}$ and $\mathrm{FSH}$ at $24 \mathrm{~h}$ before deviation, failing to confirm the results of an earlier study (Kulick et al., 2001). However, a more precipitous decrease in FSH occurred in heifers with codominant follicles after the first deviation, in agreement with the earlier study. The FSH concentrations were lower at $36 \mathrm{~h}$ and $48 \mathrm{~h}$ after the beginning of the first deviation, corresponding to the mean time of the second deviation at $36 \mathrm{~h}$. This temporal association is consistent with the proposal that an additional reduction in $\mathrm{FSH}$ is involved in the second 
deviation (Kulick et al., 2001). However, this conclusion is based only on temporal relationships.

In conclusion, both progesterone and oestradiolantiserum treatment prevented the continued decline in FSH concentrations that encompasses deviation. This result is attributable to the depression of circulating oestradiol. The treatments also resulted in a reduction in diameter of the two largest follicles at the time that deviation was beginning in controls. These changes in follicle diameter were associated with a delay in the time of deviation in both progesterone- and antiserum-treated heifers. Considering the retarded growth of follicles, it is not likely that the delayed deviation was attributable to the increased FSH. The most favoured interpretation is that both treatments reduced the availability of intrafollicular oestradiol, which caused transient follicle retardation and therefore delayed deviation.

The present study was supported by the University of Wisconsin, Madison and the Eutheria Foundation, Cross Plains, WI. The authors thank the Pharmacia Company for the gift of Lutalyse, A. F. Parlow from National Hormone and Peptide Program for gonadotrophin radioimmunoassay reagents, K. Kot for help with immunization and serum collection in goats and S. C. Jensen for technical assistance.

\section{References}

Adams GP, Matteri RL and Ginther OJ (1992a) Effect of progesterone on ovarian follicles, emergence of follicular waves, and circulating follicle stimulating hormone in heifers Journal of Reproduction and Fertility $\mathbf{9 6}$ $627-640$

Adams GP, Matteri RL, Kastelic JP, Ko JCH and Ginther OJ (1992b) Association between surges of follicle-stimulating hormone and emergence of follicular waves in heifers Journal of Reproduction and Fertility 94 177-188

Austin EJ, Mihm M, Evans ACO, Ireland JLH, Ireland JJ and Roche JF (2002) Effects of oestradiol and progesterone on secretion of gonadotropins and health of first wave follicles during the oestrous cycle of beef heifers Reproduction 124 531-541

Beg MA, Bergfelt DR, Kot K, Wiltbank MC and Ginther OJ (2001) Follicular fluid factors and granulosa-cell gene expression associated with follicle deviation in cattle Biology of Reproduction 64 432-441

Beg MA, Bergfelt DR, Kot K and Ginther OJ (2002) Follicle selection in cattle: dynamics of follicular fluid factors during development of follicle dominance Biology of Reproduction 66 120-126

Bergfelt DR, Smith CA, Adams GP and Ginther OJ (1997) Surges of FSH during follicular and early luteal phases of estrous cycle in heifers Theriogenology 48 757-768

Bley MA, Saragueta PE and Baranao JL (1997) Concerted stimulation of rat granulosa cell deoxyribonucleic acid synthesis by sex steroids and follicle stimulating hormone Journal of Steroid Biochemistry and Molecular Biology 62 11-19

Burghardt RC and Anderson E (1981) Hormonal modulation of gap junctions in rat ovarian follicles Cell Tissue Research 214 181-193

Drummond AE and Findlay JK (1999) The role of estrogen in folliculogenesis Molecular and Cellular Endocrinology 151 57-64
Fortune JE and Quirk SM (1988) Regulation of steroidogenesis in bovine preovulatory follicles Journal of Animal Science $\mathbf{6 6}$ Supplement $\mathbf{2 1 - 8}$

Ginther OJ, Wiltbank MC, Fricke PM, Gibbons JR and Kot K (1996) Selection of dominant follicle in cattle Biology of Reproduction 551187 1194

Ginther OJ, Kot K, Kulick LJ and Wiltbank (1997a) Sampling follicular fluid without altering follicular status in cattle: oestradiol concentrations early in a follicular wave Journal of Reproduction and Fertility 109 181-186

Ginther OJ, Kot K, Kulick LJ and Wiltbank MC (1997b) Emergence and deviation of follicles during the development of follicular waves in cattle Theriogenology 48 75-87

Ginther OJ, Bergfelt DR, Kulick LJ and Kot K (1999) Selection of dominant follicle in cattle: establishment of follicle deviation in less than 8 hours through depression of FSH concentrations Theriogenology 52 10791093

Ginther OJ, Bergfelt DR, Kulick LJ and Kot K (2000) Selection of dominant follicle in cattle: role of estradiol Biology of Reproduction 63 383-389

Ginther OJ, Beg MA, Bergfelt DR, Donadeu FX and Kot K (2001a) Follicle selection in monovular species Biology of Reproduction 65 638-647

Ginther OJ, Bergfelt DR, Beg MA and Kot K (2001b) Effect of LH on circulating oestradiol and follicular fluid factor concentrations during follicle deviation in cattle Reproduction 122 103-110

Ginther OJ, Bergfelt DR, Beg MA and Kot K (2001c) Follicle selection in cattle: role of luteinizing hormone Biology of Reproduction 64 197-205

Ginther OJ, Beg MA, Bergfelt DR and Kot K (2002) Activin A, estradiol, and free insulin-like growth factor $\mathbf{I}$ in follicular fluid preceding the experimental assumption of follicle dominance in cattle Biology of Reproduction 67 14-19

Hsu CJ and Hammond JM (1987) Gonadotropins and estradiol stimulate immunoreactive insulin-like growth factor-I production by porcine granulosa cells in vitro. Endocrinology 120 198-207

Hulshof SCJ, Figueiredo JR, Beckers JF, Bevers MM, van der Donk JA and van den Hurk R (1995) Effects of fetal bovine serum, FSH and $17 \beta$ estradiol on the culture of bovine preantral follicles Theriogenology $\mathbf{4 4}$ $217-226$

International Atomic Energy Agency (IAEA) (1984) Laboratory training manual on radioimmunoassay in animal reproduction. In Technical Reports Series No. 233 pp 147-154 International Atomic Energy Agency, Vienna

Kaneko H, Nakanishi Y, Akagi S, Arai K, Taya K, Watanabe G, Sasamoto S and Hasegawa $Y$ (1995) Immunoneutralization of inhibin and estradiol during the follicular phase of the estrous cycle in cows Biology of Reproduction 53 931-939

Kaneko H, Todoroki J, Noguchi J, Kikuchi K, Mizoshita K, Kubota C and Yamakuchi H (2002) Perturbation of estradiol-feedback control of luteinizing hormone secretion by immunoneutralization induces development of follicular cysts in cattle Biology of Reproduction $\mathbf{6 7}$ 1840-1845

Kanji GK (1993) 100 Statistical Tests pp 45, 171 Sage Publications, London

Kulick LJ, Bergfelt DR, Kot K and Ginther OJ (2001) Follicle selection in cattle: follicle deviation and codominance within sequential waves Biology of Reproduction 65 839-846

Richards JS (1980) Maturation of ovarian follicles: actions and interactions of pituitary and ovarian hormones on follicular cell differentiation Physiological Reviews 60 51-89

Rosenfeld CS, Wagner JS, Roberts RM and Lubahn DB (2001) Intraovarian actions of oestrogen Reproduction 122 215-226

Received 31 December 2002.

First decision 24 February 2003.

Revised manuscript received 3 March 2003.

Accepted 10 March 2003. 